ARTÍCULO

\title{
Propuestas para un modelo de educación patrimonial en la formación inicial docente de pedagogía en historia, geografía y ciencias sociales
}

\author{
Adolfo Berríos Villarroel' (D) \\ Vanessa Tessada Sepúlvedal (1) \\ Francisco Gallegos Celis'
}

\section{RESUMEN}

$\mathrm{El}$ artículo tiene por objetivo principal reflexionar sobre el enfoque educativo que necesita el docente de Historia, Geografía y Ciencias Sociales para deconstruir la retórica consensual del patrimonio en la sala de clases. Considerando las prescripciones curriculares sobre el patrimonio en la educación primaria y secundaria chilena, el texto pone en tensión el concepto de ciudadanía activa y el uso de la memoria como herramientas de una pedagogía crítica que permita cuestionar el uso instrumental de los símbolos y valores que envuelven a los hitos y sitios catalogados de patrimoniales. A partir de una lectura crítica del quehacer docente en esta asignatura escolar, el artículo aboga por un modelo de educación patrimonial socio-constructivista y crítico que, desde una perspectiva comunitarista, transforme las actividades educativas en un ejercicio de formación ciudadana que contribuya a resignificar las identidades locales y su patrimonio.

PALABRAS CLAVE

ciudadanía activa; educación patrimonial; memoria.

'Universidad Autónoma de Chile, Temuco, Chile. 


\section{PROPOSALS FOR AN HERITAGE EDUCATION MODEL IN INITIAL TEACHER TRAINING OF PEDAGOGY IN HISTORY, GEOGRAPHY, AND SOCIAL SCIENCES}

\section{ABSTRACT}

The main objective of the present article is to reflect on the educational approach that a History, Geography, and Social Science teacher needs to deconstruct the consensual rhetoric of heritage concept in classroom. Considering the curricular requirements on heritage in Chilean primary and secondary education, the text highlights the concept of active citizenship and the use of memory as tools of a critical pedagogy, which allows to question the instrumental usage of symbols and values that surround the landmarks and sites classified as heritage. Based on a critical reading of teaching duty in this school subject, the article advocates a model of socio-constructivist and critical heritage education that, from a communal perspective, transforms educational activities into a vocational training exercise that contributes to re-signify local identities and their heritage.

KEYWORDS

active citizenship; heritage education; memory.

PROPOSTAS PARA UM MODELO DE EDUCAÇÃO

PATRIMONIAL NA FORMAÇÃO INICIAL DOCENTE DE PEDAGOGIA EM HISTÓRIA, GEOGRAFIA E CIÊNCIAS SOCIAIS

\section{RESUMO}

O principal objetivo do artigo é refletir sobre a abordagem educacional que professores de História, Geografia e Ciências Sociais precisam para desconstruir a retórica consensual do patrimônio em sala de aula. Considerando as prescrições curriculares sobre o patrimônio no ensino fundamental e médio do Chile, o texto enfatiza o conceito de cidadania ativa e o uso da memória como ferramentas de uma pedagogia crítica que permite questionar o uso instrumental dos símbolos e valores que circumdam os marcos e sites listados como patrimônio. Com base em uma leitura crítica do trabalho docente nessa disciplina, o artigo defende um modelo de educação sócio-construtivista e crítica do patrimônio que, de uma perspectiva comunitária, transforma atividades educacionais em um exercício de treinamento dos cidadãos, contribuindo para ressignificar as identidades locais e sua herança.

PALAVRAS-CHAVE

cidadania ativa; educação patrimonial; memória. 


\section{CONTEXTO Y PROBLEMA}

Desde hace más de treinta años que el cuadro normativo propuesto por la UNESCO invita a los Estados a implementar medidas para salvaguardia de las distintas manifestaciones del patrimonio presentes en el territorio y en sus comunidades (UNESCO, 1972, 1989, 2003). No obstante, toda intervención sobre el patrimonio no es neutral ni imparcial. En efecto, su asimilación a una identidad social y colectiva genera cuestionamientos en torno a la funcionalidad práctica de los objetos que lo constituyen: el monumento, el sitio natural, etc. Es decir, erigido por el Estado-nación como un símbolo de cohesión, la conservación de bienes y/o tradiciones genera polémicas puesto que envuelven una serie de valores y significados. Según González-Varas (2015), se trata de un proceso variable y altamente discutible, pues los elementos del pasado considerados como patrimonio dependen de estimaciones realizadas desde el presente.

Si bien la Convención de Faro (Council of Europe, 2005) valora la salvaguardia del patrimonio como una práctica social y una posibilidad de mejorar la calidad de vida de los ciudadanos, este reconocimiento, que se impone de arriba hacia abajo, no solo neutraliza los discursos identitarios, sino que también despierta dudas sobre su legitimación social. Siguiendo a Bauman (2003), la globalización económica, política y tecnológica ha socavado el sentido de pertenencia social para dar paso a una marcada individualidad. Así, el paso de una sociedad sólida a una sociedad líquida implica un alejamiento de aquellos símbolos tradicionales que mantenían unidos a los seres humanos con la sociedad. Además, existe un cuestionamiento hacia los mecanismos oficiales de patrimonialización producto de la emergencia de memorias particulares o fragmentadas, es decir, distintas a la memoria oficial. De esta manera, este panorama otorga un carácter más dialéctico y maleable a aquellos elementos que tienen o reciben la etiqueta de patrimonial.

En Chile, la Ley General de Educación No 20.370 del año 2009 señala que corresponderá al Estado fomentar la protección del patrimonio cultural y medio ambiental, y la diversidad cultural de la Nación. Además, la Ley No 21.045 que crea el Ministerio de las Culturas, las Artes y el Patrimonio (Chile, 2017), invita a establecer un lazo permanente con la educación formal "con el fin de dar expresión a los componentes culturales, artísticos y patrimoniales en los planes y programas de estudio y en la labor pedagógica y formativa de los docentes y establecimientos educacionales"(Chile, 2017, p. 3). En este sentido, la normativa nacional considera que la escuela es fundamental para reflexionar el patrimonio cultural como un bien público y social de reconocimiento, construcción y proyección de la identidad nacional.

A nivel curricular, la asignatura escolar de Historia, Geografía y Ciencias Sociales incorpora en las bases curriculares de enseñanza básica (primaria) y media (secundaria) el concepto de patrimonio. Por ejemplo, el reconocimiento del patrimonio como símbolo de identidad y de pertenencia a una comunidad, región y del país, es una actitud transversal que los estudiantes deben desarrollar durante los seis años del ciclo de primaria (Chile, 2018). Mientras que en los restantes seis años del ciclo de secundaria (Chile, 2015), las actividades educativas relacionadas 
con el patrimonio cultural y territorial de la nación tienen como objetivo conocer y valorar su entorno social, la historia y sus actores, así como los símbolos y tradiciones.

Este enfoque instrumental del patrimonio en el curriculum de esta asignatura se transforma en pieza clave del proceso de construcción de un imaginario colectivo nacional. Carente de una propuesta desafiante que permita a los actores escolares aplicar procedimientos metodológicos para desvelar el carácter multifacético del patrimonio, el imaginario nacional que se transmite en las aulas escolares tiende a ser homogeneizante y a formar parte de la invención de la tradición. Bajo esta lógica, el relato histórico de la escuela parece orientar y legitimar el rescate del pasado cuyos actos de patrimonialización buscan la rememoración y exaltación del pasado de manera oficial y controlada. Desde este punto de vista, la educación patrimonial realizada en la escuela, apoyándose en el metarrelato histórico, mira a un pasado unívoco y no integra una dimensión política que permita cuestionar los elementos que fundan la cohesión social del Estado-nación (Trabajo y Cuenca, 2017; Domínguez-Almansa y López, 2017a, 2017b, 2017c). Es decir, más que desarrollar habilidades que permitan al alumnado entender qué elementos del pasado fueron seleccionados y bajo qué objetivos, se utiliza el patrimonio como un vestigio para sustentar el relato histórico en pos de construir el discurso de identidad nacional (Molina y Ortuño, 2017).

Con relación a la escolarización del patrimonio, cabe señalar que este proceso representa un dilema para las prácticas educativas tradicionales de la escuela. Según Barthes, Lange y Tutiaux-Guillon (2017), los conocimientos ligados al patrimonio tienen un carácter ecléctico proveniente de diversas disciplinas científicas (historia, arte, arquitectura, arqueología, etc.), lo que desafía la estructura habitual de los contenidos transmitidos por las asignaturas escolares. Por lo tanto, cada asignatura en función de su afinidad conceptual y metodológica se hace cargo de alguna temática del patrimonio. Por ejemplo, las Artes Visuales de la artesanía; Lenguaje y Literatura de la tradición oral; y la Historia, Geografía y Ciencias Sociales de los pueblos indígenas, sus tradiciones, así como de los sitios naturales. Por consiguiente, cada sector utiliza estas informaciones para señalar el objeto que se debe preservar, generando una representación parcelada del patrimonio en sus distintas manifestaciones. Además, la demanda social por la educación patrimonial y su apertura hacia lo local territorializa los contenidos curriculares, generando dudas sobre la legitimidad científica de los saberes de referencia y sus consecuencias en el proceso de didactización llevado a cabo por el docente (Barthes y Alpe, 2014).

Teniendo presente, por un lado, que la conceptualización del patrimonio involucra la manipulación del relato histórico para justificar un discurso de identidad y cohesión social y, por otro lado, el desafío pedagógico que implica su introducción en la sala de clases, es necesario reflexionar sobre el enfoque educativo que necesita el docente para cuestionar la retórica consensual que envuelve a este concepto y desde aquí, identificar los intereses políticos y económicos que vehiculan las acciones y prácticas educativas patrimoniales que habitualmente se llevan a cabo en la escuela. Considerando diferentes modelos y experiencias de educación patrimonial (Barthes y Blanc-Maximin, 2017; Aroca, 2008, 2017; Fontal, 2016a, 2016b; Fontal y Gómez, 2015; Ibarra, Bonomo y Ramírez, 2014; Ibáñez, Fontal y Cuenca, 2015; 
Stone, 2004), este trabajo tiene como propósito desarrollar competencias ciudadanas que inviten a dudar de la neutralidad que envuelve el discurso de comunidad, bien común e identidad propuesto por el nexo entre patrimonio e Historia. Atendiendo la ausencia de estudios o evaluaciones de los programas educativos implementados a nivel nacional en esta materia, esta propuesta de educación patrimonial invita a estimular la crítica acerca de las creencias que forja el discurso oficial del patrimonio, mediante el rescate de los relatos de vida y experiencias cotidianas de los estudiantes $\mathrm{y}$ sus comunidades.

\section{LA EDUCACIÓN PATRIMONIAL: DISCUSIONES Y POSIBILIDADES DESDE LA FORMACIÓN CIUDADANA}

El patrimonio parece estar supeditado a las lógicas dominantes, en tanto se impone el modelo de la educación financiera y la historia oficial en las bases curriculares y otros productos propuestos por el MINEDUC. A esto se suma que, en términos de educación no formal, el patrimonio pasaría a formar parte de la industria cultural, término acuñado por Theodor Adorno y Max Horkheimer (2007) para referirse a todos aquellos productos surgidos desde la sociedad del capitalismo, y que podría evidenciarse principalmente en su utilización dentro de una "cultura de la superficialidad" (Ávila y Mattozzi, 2009). El patrimonio se vuelve, así, un bien de consumo; iniciativas como el "Día del Patrimonio" no harían más que replicar los discursos dominantes desde la perspectiva educativa, la mirada historiográfica y los guiones museográficos. En sus dimensiones educativa e historiográfica, los bienes considerados como patrimonio quedan al margen de los mismos grupos que el modelo económico ha desprotegido. Las élites dirigentes, al elegir y legalizar el patrimonio, también lo ocultan. Los temas vinculados al patrimonio terminan por desaparecer de los currículos escolares (Ávila, 2001), anexándose, con suerte, a áreas troncales como historia y arte.

En esa línea, la propuesta que de aquí surge mira el patrimonio desde una perspectiva educativa transversal, es decir, que pueda ser aprehensible por el conjunto social (Teixeira, 2006) y garante de participación ciudadana. No en vano las propias comunidades construyen su propio pasado e identidad, resolviendo conflictos y consensuando acuerdos, forma parte de la capacidad de diálogo y participación que han ido cultivando a través del tiempo. Por lo tanto, la garantía de que el patrimonio se vuelva democrático es que las propias comunidades ejerzan su rol desde la participación ciudadana. La educación, en este panorama, adquiere relevancia. Como ha mencionado Adela Cortina (2004, p. 37), "la meta de la educación no solo debe consistir en transmitir habilidades técnicas y sociales - capital humano y social -, sino también en enseñar a incorporar valores como la libertad, la igualdad, la solidaridad, el respeto activo y el diálogo". Los individuos participan en la ciudadanía al hacer buen uso de sus derechos individuales, grupales, colectivos y también patrimoniales (Ávila y Mattozzi, 2009).

Pero una perspectiva de la educación para la ciudadanía de estas características entra en conflicto con el paradigma liberal. Este último, que toma el universalismo 
de Kant como centro de la ciudadanía, puede contradecirse en varios puntos con el fenómeno del patrimonio, que responde a la tradición de comunidades específicas - locales - más que a un cosmopolitismo. Las propuestas globalizadoras de la educación patrimonial que surgen desde el liberalismo promueven una ciudadanía nacional basada en ideales de convivencia y participación solidarios e inclusivos, pero sometida al modelo económico y político occidental. De ahí que el Estado no sólo sea garante de derechos universales de los individuos, sino que además se hace parte de decisiones como la patrimonialización de bienes culturales.

En esa línea, nuestra investigación discute el concepto de ciudadanía liberal desde las propuestas comunitaristas y republicanistas, surgidas en las últimas décadas del siglo XX. Más allá del amplio debate en torno al ideal de ciudadano que estas tradiciones han elaborado, hay ciertas conceptualizaciones que recogemos en esta propuesta.

Del comunitarismo rescatamos la representación del ciudadano social, es decir, aquel que adquiere una identidad previa desde la colectividad. En este pensamiento, la comunidad histórica a la cual los ciudadanos pertenecen está definida en la búsqueda del bien común; asimismo, se disponen pautas de convivencia que integran a los individuos en el grupo. "La completa definición de la identidad de alguien incluye, por tanto, no solo su posición en las cuestiones morales y espirituales, sino también una referencia a una comunidad definidora”, dirá Charles Taylor (1996, p. 64), considerado uno de los principales exponentes de esta corriente. Así, pensar el patrimonio desde la óptica del comunitarismo, es consistente en el hecho de que los hitos considerados patrimoniales responden a tradiciones históricas locales construidas desde la propia comunidad. La educación patrimonial promovería el fortalecimiento de la tradición histórica, ajustando el foco en procesos locales, en los cuales la participación de los individuos se formule desde el diálogo abierto.

El republicanismo, en tanto, si bien comparte tópicos con el comunitarismo, promueve una concepción de identidad que no depende de la tradición, sino más bien del "diálogo con la comunidad viviente" (Anchustegui, 2011), con generaciones actuales que deciden modos de vida y ámbitos de acción. Visto de otro modo, el republicanismo es un modo de vida compartido que suscita la participación activa de los ciudadanos. El patrimonio, mirado desde el republicanismo, es vivencial en la medida que la comunidad actual participa a través del diálogo tanto en su definición ¿qué es patrimonio? como en la identificación de aquellos elementos que pueden ser patrimonializables.

Con todo, la ciudadanía activa, desde las comunidades, ofrece posibilidades ciertas de rescate, salvaguarda y promoción de los bienes culturales que son identificados como patrimonio. No en vano, en las últimas dos décadas han surgido diversas propuestas que vinculan la Educación Patrimonial con la ciudadanía activa, advirtiendo sobre su necesidad y opciones de implementación desde la interdisciplinariedad en las aulas escolares. Una de ellas es la propuesta por Teixeira (2006), quien sostiene que la Educación Patrimonial se formula desde una praxis educativa y social, permitiendo que los estudiantes perciban su dimensión histórica y fortalezcan compromisos sociales. Asimismo, en términos de las comunidades, una educación patrimonial favorecería "las economías locales a través del desarrollo turístico y de 
la sustentabilidad, fortaleciendo además el sentimiento de pertenencia y los lazos afectivos entre los miembros de la comunidad" (Teixeira, 2006, p. 138). Teixeira es consciente, en este último sentido, que la Educación Patrimonial puede replicar el enfoque de la Educación Ambiental, en la medida en que pueden identificarse productos significativos que permitan generar conciencia, compromiso y alcanzar la ciudadanía. No obstante, esta propuesta incluye aspectos sustanciales que podrían ser garantes de la participación ciudadana, hay ciertos elementos que continúan identificando al patrimonio como bien de consumo desde el punto de vista del modelo capitalista, cuando se le incluye dentro de prácticas turísticas y economicistas.

Rosa Ávila e Ivo Mattozzi (2009) señalan, desde una postura vinculada con la didáctica del patrimonio, que las escuelas deben optar por modelos que enriquezcan el conocimiento de los estudiantes, con visiones que complejicen y critiquen las realidades patrimoniales que permitan la participación responsable. Estos autores comparten la idea de que el patrimonio debe reconceptualizarse, en el entendido de que "es el signo de identidad más importante que, a partir del último siglo, tiene la sociedad" (Avila y Mattozzi, 2009, p. 342). Si bien es cierto discutimos parte de la definición (cuando menciona por ejemplo que "el patrimonio somos nosotros mismos", lo que podría generar interpretaciones equívocas sobre su referencia), adherimos a la idea de que el patrimonio ha sido utilizado en ocasiones con fines políticos e ideológicos manipuladores de la ciudadanía. Por ello, su propuesta desde la responsabilidad ciudadana involucra, necesariamente, a la educación. La preservación del patrimonio requiere de una actitud crítica y solidaria, iniciándose desde "una formación deseable del profesorado implicado en la educación patrimonial, basado en el diseño y experimentación de propuestas de participación ciudadana, vinculadas a la intervención social" (Ávila y Mattozzi, 2009, p. 351).

Como tal, es un hecho que la educación patrimonial merezca ser revisada desde los componentes fundamentales de la ciudadanía. Eso significa también que debe promover contenidos democráticos que se conciban desde iniciativas abiertas al diálogo consensuado. Una educación patrimonial, desde esa esfera, se cristaliza en individuos capaces de vivir en valores y normas de las comunidades, que a través de las tradiciones perviven en el ethos de las comunidades (Cortina, 2004, 2011). A través de ellas surgen procesos colectivos desde los cuales se constituyen la experiencia y la identidad. Así, una educación patrimonial, desde un diálogo racional, debiese estar enfocada en las vivencias y memorias personales y colectivas que dan significado a su comunidad.

\section{MEMORIA Y SUS APORTES PARA LA CONSTRUCCIÓN DEL PATRIMONIO DESDE LA COMUNIDAD}

La idea de nación y la construcción de los estados modernos se realizó desde la construcción de un pasado colectivo cuyos efectos debían ser homogeneizantes. En este sentido, el constructo Nación se eleva sobre una narrativa continua de progreso nacional que articular la idea de un pasado común y una clara identidad nacional, es decir, la Nación es la "fuerza simbólica" que permite la existencia de las comunidades nacionales desde el siglo XIX (Bhabba, 2010). En este escenario, la Historia 
en tanto disciplina científica se encargó de generar la "verdadera historia del pasado" (Wallerstein, 2006) y sirvió a la construcción de los estados nacionales a partir de la cientifización del conocimiento del pasado. La principal fuente que permitió tal construcción fueron los archivos oficiales, entendidos como objetivos y verdaderos. Pese a ello, la elaboración del pasado común necesita de un ingrediente emotivo, el que ha venido de la mano de la localización de espacios simbólicos y el levantamiento de monumentos que conmemoran constantemente los hitos vertebradores del gran metarrelato nacional, algunos de ellos acompañados de conmemoraciones que traen al presente el pasado común. A la luz de esta lógica, el patrimonio nacional es entendido como los monumentos y sitios que honran a héroes nacionales y hechos políticos y militares, generando discursos tradicionales, totalizantes y que oscurecen contranarrativas subalternas (Márquez, 2019). Es decir, la Historia ha sido la encargada de orientar y legitimar la narración sobre el pasado de manera oficial y controlada, cuyo relato esconde la vida de quienes habitan las naciones.

El proceso de globalización, la instalación del modelo neoliberal y el asomo de la posmodernidad han detonado la crisis del paradigma histórico, pues han puesto en entredicho las ideas de continuidad, homogeneidad y fronteras, deconstruyendo los grandes metarrelatos que alimentaron la existencia de las colectividades nacionales. En este escenario, la historia ha cedido terreno en favor de nuevos enfoques, teorías y metodologías de acercamiento al pasado, antes desacreditadas y deslegitimadas, lo que ha afectado también la construcción del patrimonio cultural (Hernández I Martí, 2008). La "memoria" ha jugado aquí un papel protagonista, en tanto una serie de procesos históricos (descolonización, emergencia de nuevos movimientos sociales y justicia y reparación de la violación de los derechos humanos) han impulsado la construcción de historiografías alternativas que integran nuevos sujetos sociales. Sujetos que al traer a la luz relatos de eventos traumáticos y sucesos conflictivos permiten reconstruir una "memoria colectiva" que pone en disputa la memoria oficial y las memorias subterráneas que emergen rehabilitando la periferia y la marginalidad (Pollak, 2006).

En América Latina, los estudios sobre memorias se han desarrollado en el contexto de las memorias traumáticas de períodos de excepción y en el reconocimiento de las violaciones de derechos humanos (se destacan los trabajos realizados en Argentina, Chile y Colombia). Sin embargo, el desarrollo del campo de estudios de las memorias aboga superar las memorias de violencia política y represión para pensarlas como memorias sociales que integren también otros conflictos causados por las desigualdades civiles, económicas, culturales e históricas. De esta manera, la visibilización de estas memorias subterráneas y su rehabilitación histórica permitirían la reconstrucción socio-identitaria de las comunidades, a la vez que consolidaría ciudadanías activas que trabajarían en pos de la construcción democrática de las naciones. Esto no quiere decir que la rehabilitación de las memorias sociales permita su oficialización pues, como dicen E. Jelin (2012), en muchas ocasiones la violencia estatal no puede ser resarcida ya que lo específico de la memoria es que es abierta, sujeta a debate y en constante proceso de revisión.

Pese a ello, en las últimas décadas se ha asistido a una suerte de institucionalización de "políticas de la memoria", lo que ha derivado en una irrupción de la 
instalación de la temática en los medios masivos de comunicación, en la literatura y otras producciones culturales, un estallido de la memoria, al decir de P. Nora (2009). Esta recuperación del pasado la vemos a diario en la moda retro, el marketing de la nostalgia y la protección del patrimonio (Huyssen, 2002). Este movimiento de memoria ha puesto como el centro de la recuperación del pasado al sujeto, su subjetividad y emotividad. Lo que nos dice que es la experiencia subjetiva la que permite que la memoria se convierta en una herramienta para acercarse a la "textura de la vida y la verdad albergada en la rememoración de la experiencia” (Sarlo, 2005, p. 21), lo que pone en duda el relato histórico tradicional cuestionando la "fuente", el "documento" y el "archivo". La tensión provocada entre memoria e historia es evidente, pese a ello, entendemos que la intrusión de la subjetividad en la disciplina supone un giro democratizador en su construcción, en el presente y el pasado que se rescata, ya que empodera la acción ciudadana en la co-construcción de los saberes sobre el pasado y la historia.

De ahí que la historia para su propia renovación necesitaría integrar las memorias, haciéndose parte del escenario democratizador que su rescate promueve. Es necesario que la historia reconozca individuos y colectivos marginados e invisibilizados, que traiga al presente memorias reprimidas y silenciadas y dé a conocer historias diversas, alternas e incluso reñidas con la oficial con el objetivo de generar lazos y construir identidades, ya no desde el afán homogeneizador prístino de la disciplina sino desde la diferencia. En este escenario, lo que entendemos por patrimonio nacional se vería transformado. Si el rescate patrimonial y la patrimonialización se enfoca en la comunidad y en lo local y se realiza a partir del rescate crítico de las memorias sociales, se convertiría en una herramienta que permitiría la recuperación del pasado disidente, pues posibilitaría reelaborar y resignificar espacios materiales e inmateriales, reafirmando la posibilidad de atribuir valor a elementos antes carentes de él, en un ejercicio que fomentaría prácticas democráticas e identitarias. De manera que el uso de las memorias faculta la construcción de un nuevo acervo patrimonial cimentado en una ciudadanía activa. El cuidado debe estar puesto en alejar este rescate patrimonial de olas nostálgicas propiciadas por el marketing y otras prácticas despolitizadoras, pues entendemos que el trabajo con el patrimonio se debe realizar desde y para la construcción crítica de identidades locales y comunitarias.

\section{UN MODELO DE EDUCACIÓN PATRIMONIAL EN HISTORIA, GEOGRAFÍA Y CIENCIAS SOCIALES}

Considerando las ambivalencias que esconde el discurso de comunidad e identidad nacional que moviliza la enseñanza de la Historia escolar, es necesario un enfoque educativo que permita a docentes y estudiantes utilizar la educación patrimonial como un recurso que contribuya a la alfabetización cultural y ciudadana. Es decir, que por un lado incite a cuestionar la herencia sociocultural propuesta por el patrimonio y, por otro lado, desarrolle competencias que permita a los actores escolares debatir y tomar posición sobre la complejidad que implica la salvaguardia del patrimonio. 
Bajo esta perspectiva, tanto los sitios e hitos patrimoniales, así como los actos de patrimonialización son objeto de críticas. Por lo tanto, la educación patrimonial se transforma en un recurso que favorece la formación ciudadana preparando a los escolares a los ejercicios y desafíos democráticos. En este sentido, Dewey (1998) señala que es indispensable que las prácticas pedagógicas permitan vivenciar y experimentar en la sala de clases los valores democráticos como: diálogo, tolerancia, respeto. De esta manera, la discusión a propósito de los elementos culturales, políticos y sociales que integran el patrimonio evita que la democracia se transforme en un concepto vacío y enriquece la formación ciudadana del educando a través de competencias transversales. Es decir, abordar el patrimonio en la sala de clases significa generar un clima de respeto mutuo y tolerancia que facilite la apertura hacia las diferencias étnicas, lingüísticas y culturales y paralelamente, promueva el diálogo sobre las cuestiones socio-identitarias presentes en nuestro país.

En este enfoque crítico y ciudadano de la educación patrimonial, la pedagogía ocupa una dimensión política que invita a revisar los símbolos colectivos que fundan la cohesión social. En este sentido, la pedagogía crítica de Paulo Freire (2009) se transforma en una herramienta de indagación que podría despertar la curiosidad epistemológica de los educandos hacia las estructuras de dominación que participan en la construcción social del patrimonio. Es decir, interrogar qué se entiende por patrimonio, a través de una lectura crítica de sus valores y del sentido identitario que se otorgan a ciertos hitos patrimoniales en la sociedad. Este tipo de cuestionamiento es fundamental en las prácticas educativas para incentivar a profesores y escolares a tomar conciencia de que son sujetos históricos y, por ende, pueden transformar la realidad que la dimensión identitaria del patrimonio legitima en la consciencia colectiva. Por lo tanto, para evitar la folclorización de la herencia cultural y social de la humanidad (Jeudy, 2001), la educación patrimonial debe considerarse como un recurso que ayuda a entender lo patrimonial como un proyecto político abierto donde todos los actores están llamados a participar a través de sus significaciones e interpretaciones del pasado.

Para contribuir a superar la representación del patrimonio como un depósito de la historia y la memoria oficial, la Figura 1 propone un modelo de educación patrimonial que invita a considerar las actividades educativas como un recurso de formación ciudadana. Apoyándose en el uso de la memoria como herramienta de resignificación social y emocional de la ciudadanía hacia los sitios e hitos designados como patrimoniales, este modelo estimula la crítica hacia los discursos y prácticas sociales habitualmente promovidas por el sistema educativo nacional en materia patrimonial. El objetivo es que las actividades educativas ayuden a revelar la complejidad que esconden los actos de patrimonialización y los distintos valores y juegos de interés que conjuga la utilización del patrimonio como símbolo de identidad colectiva. Por lo tanto, este modelo pretende avanzar hacia una concepción dinámica y comunitaria del patrimonio, puesto que es la sociedad civil quien, en última instancia, se reconoce o se identifica con sus símbolos y significados.

De esta manera, la Figura 1 es el resultado del cruce de un eje vertical que representa el paradigma de ciudadanía que envuelve a las actividades patrimoniales y un eje horizontal que refleja la postura pedagógica que adopta el futuro docente 


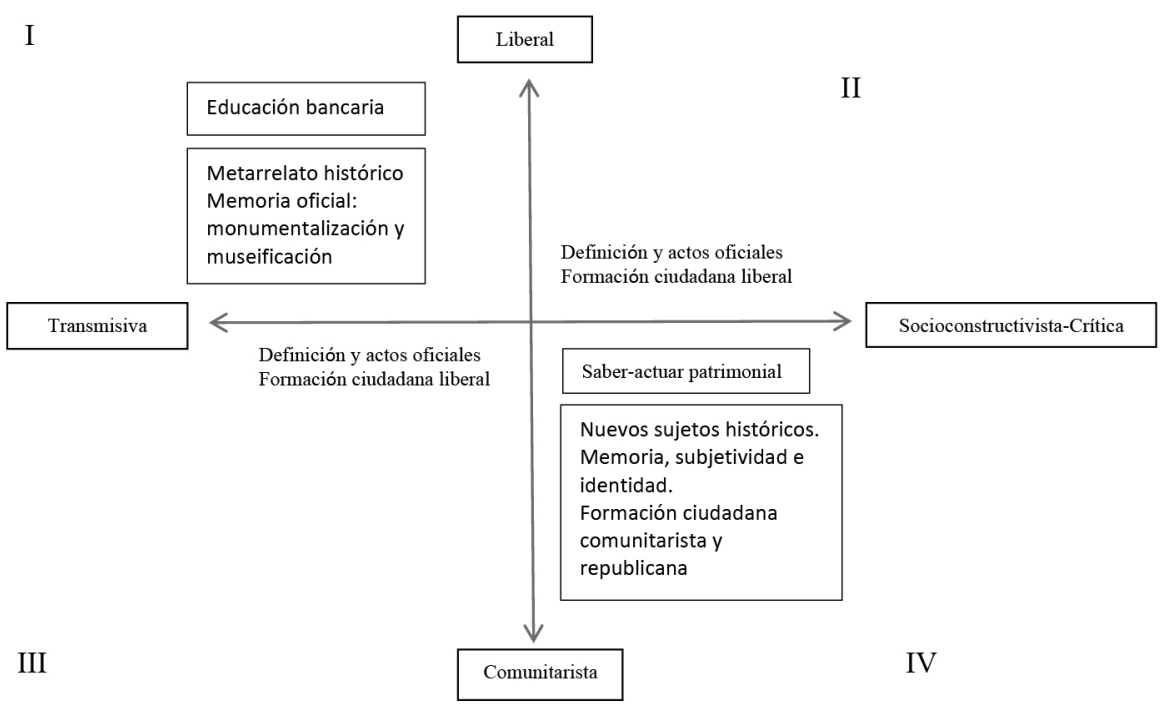

Figura 1-Modelo de educación patrimonial en la formación inicial de Pedagogía en Historia, Geografiay Ciencias Sociales.

para abordar este tipo de temáticas en clases. El cruce de ambos ejes da como resultado cuatro cuadrantes que entregan pistas sobre las orientaciones que pueden seguir las actividades educativas en esta materia.

En el cuadrante I, el docente actúa como canal de transmisión de los valores, informaciones, conocimientos, hitos y sitios definidos por los grupos de poder en relación con el patrimonio. Se trata de una educación bancaria del patrimonio (Freire, 2004), donde el docente deposita en el estudiante el discurso de identidad acuñado por el metarrelato histórico y la memoria oficial. Utilizando como recursos la museificación y la monumentalización (batallas, presidentes, etc.), este tipo de educación patrimonial tiene como propósito que el estudiante archive y memorice los símbolos que sirven como referentes de la identidad nacional. Por lo tanto, esta educación bancaria considera al patrimonio de manera estática y excluyente, puesto que el proceso de patrimonialización opera desde lo institucional. Este carácter impositivo aleja la crítica e instrumentaliza la ciudadanía en favor de actitudes y comportamientos favorables a la conservación del patrimonio oficial. Es decir, no existe el desarrollo de competencias que permitan cuestionar los valores y significados de los referentes patrimoniales, por lo que, desde la historia, el estudio del patrimonio se reduce a rememorar ciertas tradiciones e hitos del pasado con el fin de legarlos a las futuras generaciones.

Los cuadrantes II y III representan etapas intermedias puesto que, si bien las actividades de enseñanza-aprendizaje reconocen el valor educativo del patrimonio y su contribución a la formación ciudadana, las ideologías subyacentes que moviliza el patrimonio no son cuestionadas Para esto, utilizan distintas metodologías que tienen como meta desarrollar actitudes cívicas como el respeto, la responsabilidad, 
la tolerancia y así generar aprendizajes que valoren el patrimonio como símbolo de la identidad y el bien común de una sociedad democrática. Apoyándose en conceptos y propuestas educativas institucionalizadas como, por ejemplo, el día del patrimonio, se invita a los actores escolares a gestionar la herencia cultural patrimonial presente en su territorio, pero no se incita a redescubrir el tejido histórico y social que justifica dicha herencia. En este sentido, el patrimonio es utilizado más bien como un recurso didáctico para vincular a los alumnos con sus raíces culturales y tradiciones. Así, en el caso de las prácticas educativas encasilladas en el segundo cuadrante se emplean metodologías que permiten un rol más activo y el contacto directo del estudiante con su patrimonio más cercano e invitan a reflexionar sobre temáticas patrimoniales de interés nacional. En el tercer cuadrante, aunque se favorece el reconocimiento del patrimonio desde una perspectiva sociohistórica y comunitaria, es el docente el hilo conductor del proceso limitando la autonomía del estudiante en la construcción de significados.

El cruce de la dimensión socioconstructivista-crítica y comunitarista representada por el cuadrante IV, favorecería la construcción de una ciudadanía activa y deliberativa a propósito del patrimonio. Siguiendo las teorías constructivistas de autores como Lev Vygotsky (2003), Jerome Brunner (1984), entre otros, las prácticas educativas favorecen el rescate de los conocimientos previos de los educandos sobre el patrimonio para favorecer aprendizajes colaborativos y significativos. Por lo tanto, se utiliza el entorno sociocultural para que el estudiante experimente de manera vivencial las dimensiones sociales, culturales, económicas y políticas que rodean a los sitios y/o hitos considerados como patrimonio. De esta manera, apoyándose en el rescate de las memorias sociales, se favorece una formación ciudadana comunitarista y republicana que busca formar ciudadanos capaces de cuestionar el lugar que ocupa la comunidad en la definición y selección de los bienes patrimoniales que conforman su identidad local. Bajo esta perspectiva, la educación patrimonial no consiste solo en participar en la conservación del patrimonio para dar respuesta a la demanda institucional, sino que también el proceso educativo contribuye a desarrollar un saber-actuar patrimonial que prepara a los futuros ciudadanos para participar en los debates y establecer acuerdos frente a la dimensión axiológica que envuelve a este concepto.

\section{CONCLUSIÓN}

La implementación de toda propuesta de educación patrimonial en la escuela requiere una discusión preliminar de su contenido. Es decir, considerado como un fenómeno cultural que depende de las distintas clases y grupos que conforman la sociedad, así como también de los individuos que la integran (Maroevic, 1998), el proceso formativo en Historia, Geografía y Ciencias Sociales debe integrar herramientas pedagógicas y didácticas que permitan al futuro docente problematizar las tensiones que esconde este concepto. Es decir, si el proceso de enseñanza-aprendizaje de la Historia, Geografía y Ciencias Sociales quiere promover la emancipación del sujeto histórico, la sala de clases no puede transformarse solo en un espacio de difusión del patrimonio material e inmaterial. Por el contrario, el proceso educativo, 
tanto en esta asignatura como en el resto, es preparar una ciudadanía crítica y activa frente a los procesos decisionales que conlleva el patrimonio.

De esta manera, considerando que el patrimonio es siempre cultural, sugerimos que esta problematización debe contribuir a cuestionar las significaciones que este elemento vehicula en sí mismo (identidad, cohesión social), y a la vez, el espacio social donde se legitima. Por ejemplo, el Ramal Talca-Constitución ${ }^{1}$ es objeto patrimonial en su materialidad - el tren, las estaciones, los rieles - y, a la vez, adquiere significación cultural para la comunidad de la Región del Maule, en la medida que integra la racionalidad humana y emocional vinculada a una comunidad.

Entonces, frente al vacío que existe en las instituciones formadoras sobre las controversias y polémicas que rodean al patrimonio como vector de identidad, es necesario formar un docente con competencias disciplinarias que le permitan cuestionar en qué medida la afinidad que establece la Historia con los objetos e hitos patrimoniales legitima el modelo sociopolítico vigente. Nos parece que mediante el debate y la confrontación de las diversas posturas que implica el rescate de las memorias sociales, la educación patrimonial se transforma en una experiencia de formación ciudadana que contribuye a resignificar lo patrimonial. Considerando la demanda por la salvaguardia del patrimonio, es necesario desarrollar competencias ciudadanas que permitan identificar no solo el valor histórico o de antigüedad de un hito o sitio, sino que también los símbolos y representaciones que asocia la comunidad. Por lo tanto, la educación patrimonial involucra reconocer su dimensión afectiva de pertenencia a una comunidad y por ende, a la comunidad escolar como actores y gestores de la política patrimonial local.

Por último, si bien la formación teórica y metodológica de los futuros docentes de Historia, Geografía y Ciencias Sociales es fundamental para trabajar el patrimonio local desde una perspectiva emocional y subjetiva, queda la interrogante si el curriculum escolar aporta los recursos necesarios para comprender su carácter multidimensional e interdisciplinario. En efecto, para conocer, valorar y conservar el patrimonio como miembros activos de la sociedad se necesitan herramientas curriculares que inciten a examinar este objeto más allá que un mero contenido. Es decir, como un vector para cuestionar en qué medida los símbolos que articulan la identidad potencian el respeto a la diversidad social y cultural para la convivencia democrática.

\section{REFERENCIAS}

ADORNO, T.; HORKHEIMER, M. Dialéctica de la ilustración. Madrid: Akal, 2007. ANCHUSTEGUI, E. Derechos humanos y modelos de ciudadanía. Límite, v. 6, n. 24, p. 9-28, 2011.

1 Tren de trocha angosta en Chile que conecta desde 1915 la ciudad de Talca con el puerto de Constitución. Tiene una extensión de 88 kilómetros, y fue declarado Monumento Histórico Nacional el 25 de mayo de 2007 (Fernández y Morales, 2005). 
AROCA, C. Educación patrimonial: una propuesta didáctica globalizadora. Santiago: Ediciones Altazor, 2008.

AROCA, C. Didáctica del patrimonio: métodos y estrategias para trabajar en educación. Santiago: Editorial LOM, 2017.

ÁVILA, R. Historia del arte, enseñanza y profesores. Sevilla: Díada, 2001.

ÁVILA, R.; MATTOZZI, I. La didáctica del patrimonio y la educación para la ciudadanía. In: ÁVILA, R.; BORGHI, B.; MATTOZZI, I. (org.). La educación de la ciudadanía y la formación del profesorado: un proyecto educativo para la "estrategia de Lisboa”. Bologna: Patron, 2009. p. 327-352.

BARTHES, A.; ALPE, Y. L'éducation au patrimoine dans les aires territoriales protégées, une dimension de l'éducation au développement durable? In:DIEMER, A. ; MARQUAT, C. (org.). Education au développement durable : enjeux et controverses. Paris: De Boeck Supérieur, 2014. p. 323-340.

BARTHES, A.; BLANC-MAXIMIN, S. Quelles évolutions de l'école française face à l'éducation au patrimoine? Revue des Sciences de L'éducation, Québec , v. 43, n. 1, p. 85-115, 2017. Disponible en: https://www.erudit.org/fr/revues/rse/2017-v43-n1rse03267/1042075ar/. Acceso en: 28 oct. 2019. https://doi.org/10.7202/1042075ar

BARTHES, A.; LANGE, J.-M.; TUTIAUX-GUILLON, N. Dictionnaire critique des enjeux et concepts des «éducations à ". Paris: L'Harmattan, 2017.

BAUMAN, Z. Modernidad líquida. Buenos Aires: Fondo de Cultura Económica de Argentina, 2003.

BHABBA, H. (org.). Nación y narración: entre la ilusión de una identidad y las diferencias culturales. España: Siglo XXI, 2010.

BRUNNER, J. Acción, pensamiento y lenguaje. Madrid: Editorial Alianza, 1984.

CHILE. Ministerio de Educación. Ley General de Educación no 20.370. Chile, 2009. Disponible en: https://www.leychile.c//Navegar?idNorma=1006043. Acceso en: 7 nov. 2019. CHILE. Ministerio de Educación. Bases curriculares $7^{\circ}$ básico a $2^{\circ}$ médio. Chile: Ministerio de Educación, 2015. Disponible en: https://media.mineduc.cl/wp-content/ uploads/sites/28/2017/07/Bases-Curriculares-7\%C2\%BA-b\%C3\%A1sico-a2\%C2\%BA-medio.pdf. Acceso en: 8 nov. 2019.

CHILE. Ministerio de Educación. Ley que crea el Ministerio de las Culturas, las Artes y el Patrimonio no 21.045. Chile, 2017. Disponible en: https://www.leychile. cl/Navegar?idNorma=1110097. Acceso en: 8 nov. 2019.

CHILE. Ministerio de Educación. Bases curriculares primero a sexto básico. Chile: Ministerio de Educación, 2018. Disponible en: https://www.curriculumnacional.cl/614/ articles-22394_bases.pdf. Acceso en: 8 nov. 2019.

CORTINA, A. Educar personas y ciudadanos democráticos. Anales de la Cátedra Francisco Suárez, v. 38, p. 29-45, 2004. https://doi.org/10.30827/acfs.v38i0.1067 CORTINA, A. Ciudadanía democrática: ética, política y religión. XIX Conferencias Aranguren. Isegoría. Revista de Filosofía Moral y Política, n. 44, p. 13-55, ene.-jun. 2011. 
COUNCIL OF EUROPE. Convention on the Value of Cultural Heritage for Society. Faro: Council of Europe, 2005. (Council of Europe Treaty Series, 199). Disponible en: https://www.coe.int/en/web/conventions/full-list/-/conventions/ rms/0900001680083746. Acceso en: 7 nov. 2019.

DEWEY, J. Democracia y educación. Madrid: Ediciones Morata, 1998.

DOMÍNGUEZ-ALMANSA, A.; LÓPEZ, R. Formación de maestros y educación patrimonial. Estudios Pedagógicos, Valdivia, v. 43, n. 4, p. 49-68, 2017a. Disponible en: http://revistas.uach.cl/pdf/estped/v43n4/art03.pdf. Acceso en: 8 nov. 2019. https:// doi.org/10.4067/S0718-07052017000400003

DOMÍNGUEZ-ALMANSA, A.; LÓPEZ, R. Memoria histórica, patrimonio y formación del profesorado de educación primaria. In: MOLINA, S.; LLONCH, N.; MARTÍNEZ,T. (org.). Identidad, ciudadanía y patrimonio: educación histórica para el siglo XXI. Gijón: Trea, 2017b. p. 71-86.

DOMÍNGUEZ-ALMANSA,A.; LÓPEZ, R. Patrimonios en conflicto, competencias cívicas y formación profesional en educación primaria. Revista de Educación, Madrid, n. 375, p. 86-109. 2017c. Disponible en: https://minerva.usc.es/xmlui/bitstream/ handle/10347/15805/2016_RevEducacion_DominguezAlmansa_Patrimonios. pdf? sequence=2\&isAllowed=y. Acceso en: 8 nov. 2019. https://doi.org/10.4438/1988592X-RE-2016-375-336

FERNÁNDEZ, B.; MORALES, A. Ramal Talca-Constitución. Un viaje en el tren del Maule. Santiago: LOM, 2005.

FONTAL, O. Educación patrimonial: retrospectiva y prospectivas para la próxima década. Estudios Pedagógicos XLII, Valdivia,v.42,n.2,p. 415-436,2016a. Disponible en: https:// scielo.conicyt.cl/scielo.php?script=sci_arttext\&pid=S0718-07052016000200024. Acceso en: 7 nov. 2019. https://doi.org/10.4067/S0718-07052016000200024

FONTAL, O. El Observatorio de Educación Patrimonial en España. Cultura y Educación, Barcelona, v. 28, n. 1, p. 261-266, 2016b.

FONTAL, O.; GÓMEZ, C. Evaluación de programas de programas educativos que abordan los procesos de patrimonialización. In: FONTAL, O.; GÓMEZ, C. Didáctica de las ciencias experimentales y sociales. Valencia: Departamento de Didáctica de las Ciencias Experimentales y Sociales, 2015. n. 29. p. 89-118.

FREIRE, P. Pedagogía de la autonomía. Sao Paulo: Paz e Terra, 2004.

FREIRE, P. Pedagogía del compromiso. América Latina y Educación Popular. Barcelona: Hipatia Editorial, 2009.

GONZÁLEZ-VARAS, I. Patrimonio cultural: conceptos, debates y problemas. Madrid: Ediciones Cátedra, 2015.

HERNÁNDEZ I MARTÍ, G. Un zombi de la modernidad: el patrimonio cultural y sus límites. La Torre del Virrey, España, n. 5, p. 27-38, 2008.

HUYSSEN, A. En busca del futuro perdido: cultura y memoria en tiempos de globalización. México: Fondo de Cultura Económica, 2002. 
IBÁÑEZ, A.; FONTAL, O.; CUENCA, J. M. Actualidad y tendencias en Educación Patrimonial. Educatio Siglo XXI, Murcia, v. 33, n. 1, p. 11-14, 2015.

IBARRA, M.; BONOMO, M.; RAMÍREZ, C. El patrimonio como objeto de estudio interdisciplinario. Reflexiones desde la educación formal chilena. Polis, Santiago, v. 13, n. 39, p. 373-391, 2014. https://doi.org/10.4067/S0718-65682014000300017

JELIN, E. Revisitanto el campo de las memorias: un nuevo prólogo. In: JELIN, E. Los trabajos de la memoria. Lima: Instituto de Estudios Peruanos, 2012. Disponible en: https://www.ides.org.ar/node/3115. Acceso en: 10 mar. 2021.

JEUDY, H.-P. Patrimoines en folie. Paris: Éditions de la Maison des Sciences del Homme, 2001.

MAROEVIC, I. The phenomenon of cultural heritage and the definition of a unit of material. Nordisk Museologi, Oslo, n. 2, p. 135-142, 1998. https://doi.org/10.5617/ nm.3829

MÁRQUEZ, F. (org.). Patrimonio: contranarrativas urbanas. Santiago: Editorial Universidad Alberto Hurtado, 2019.

MOLINA, S.; ORTUÑO, J. Concepciones del profesorado iberoamericano de Secundaria sobre la contribución del patrimonio local al desarrollo del pensamiento histórico. Estudios Pedagógicos, Valdivia, v. 43, n. 4, p. 185-202, 2017. Disponible en: http://revistas.uach.cl/pdf/estped/v43n4/art10.pdf. Acceso en: 8 nov. 2019. https://doi. org/10.4067/S0718-07052017000400010

NORA, P. Pierre Nora en Les lieux de mémoire. Santiago: LOM Ediciones y Trilce, 2009. ORGANIZACIÓN DE LAS NACIONES UNIDAS PARA LA EDUCACIÓN, LA CIENCIA Y LA CULTURA (UNESCO). Convención sobre la protección del patrimonio mundial, cultural y natural. París: UNESCO, 1972. Disponible en: https:// whc.unesco.org/archive/convention-es.pdf. Acceso en: 7 nov. 2019.

ORGANIZACIÓN DE LAS NACIONES UNIDAS PARA LA EDUCACIÓN, LA CIENCIA Y LA CULTURA (UNESCO). Recomendación sobre la Salvaguardia de la Cultura Tradicional y Popular. París: UNESCO, 1989. Disponible en: https:// unesdoc.unesco.org/ark:/48223/pf0000084696_spa.page=252. Acceso en: 6 nov. 2019 . ORGANIZACIÓN DE LAS NACIONES UNIDAS PARA LA EDUCACIÓN, LA CIENCIA Y LA CULTURA (UNESCO). Convención para la salvaguardia del patrimonio cultural inmaterial. París: UNESCO, 2003. Disponible en: https:// unesdoc.unesco.org/ark:/48223/pf0000132540. Acceso en: 6 nov. 2019.

POLLAK, M. Memoria, olvido, silencio: la producción social de identidades frente a situaciones límite. La Plata: Ediciones Al Margen, 2006.

SARLO, B. Tiempo pasado: cultura de la memoria y giro subjetivo. Una discusión. Buenos Aires: Siglo XXI, 2005.

STONE, P. Introduction: Education and the historic environment into the twenty-first century. In: HENSON, D.; STONE, P.; CORBISHLEY, M. (org.). Education and the historic environment. London: Routledge, University of Newcatle, 2004. p. 1-10. TAYLOR, C. Fuentes delyo: la construcción de la identidad moderna. Barcelona: Paidós, 1996. 
TEIXEIRA, S. Educación patrimonial: alfabetización cultural para la ciudadanía. Estudios Pedagógicos, Valdivia, v. 32, n. 2, p. 133-145, 2006. https://doi.org/10.4067/ S0718-07052006000200008

TRABAJO, M.; CUENCA, J. M. La educación patrimonial para la adquisición de competencias emocionales y territoriales del alumnado de enseñanza secundaria. Pulso, Madrid, n. 40, p. 159-174, 2017.

VYGOTSKY, L. El desarrollo de los procesos cognitivos superiores. Barcelona: Paidós, 2003.

WALLERSTEIN, I. (coord.). Abrir las ciencias sociales. Informe de la Comisión Gulbenkian para la reestructuración de las ciencias sociales. México: Siglo XXI, 2006.

\section{SOBRE LOS AUTORES}

Adolfo Berríos Villarroel es doctor en ciencias de la educación por la Aix-Marseille Université (Francia). Profesor de la Universidad Autónoma de Chile (Chile). E-mail: adolfo.berrios@uautonoma.cl

Vanessa Tessada Sepúlveda es doctora en historia por la Universidad de Valladolid (España). Profesora de la Universidad Autónoma de Chile (Chile). E-mail:vanessa.tessada@uautonoma.cl

Francisco Gallegos Celis es doctor en historia por la Pontificia Universidad Católica de Chile (Chile). Profesor de la Universidad Autónoma de Chile (Chile).

E-mail: francisco.gallegos@uautonoma.cl

Conflictos de interes: No existen conflictos de interés.

Financiamento: Proyecto interno financiado por la Universidad Autónoma de Chile, DIUA 154-2019.

Contribuiciones de los autores: Administración del Proyecto, Análisis Formal, Conceptualización, Escrita - Primera Redacción, Obtención de Financión, Metodología: Villarroel, A.B. Análisis Formal, Escrita - Revisión y Edicción, Supervisión, Validación, Visualización: Sepúlveda, V.T.: Celis, F.G.

Recibido el 2 de diciembre de 2019

Aprobado el 24 de agosto de 2020 